\title{
Knowledge and Attitudes Regarding Health Education among Sample of Iraqi Patients Attending Primary Health Care Centers
}

${ }^{1}$ Lujain A. Alkhazrajy

\section{ABSTRACT}

Background: Health education was put as one of the components of primary health care elements and was recognized as a fundamental tool to the attainment of health for all

Objective: To evaluate the Knowledge, attitude regarding health education $\&$ to find out if there is any association between the gathered data and certain variables (age, gender, educational level, occupation). Methods: A Cross-sectional study done at Al Mustansyryia Primary Health Care Center from the $1^{\text {st }}$ of January to $1^{\text {st }}$ of May 2016. All patients attending the Primary Health Care Centers who were above 18 years of age and willing to participate in the research (303) were included in the sample, data was collected by structured questionnaire, \& then introduced into Statistical Package for the Social Sciences,V.17 for statistical analysis. Chi-square test was computed for significance of difference, and $\mathrm{P} \leq 0.05$ was considered significant

Results: The highest group of age was (18-30) years old, $(51.5 \%)$ were male, $(35.3 \%)$ of participants are of high school education. The participants had good knowledge about health education. There was a significant association regarding knowledge, with ages and educational levels of participants, with no association regarding the gender and occupation. There was no association regarding attitude with these variables. Most of the of participants showed positive attitudes about health education as a practice

Conclusion: The participants had good knowledge about health education, and positive attitude.

Key words: knowledge, Attitude, health education, primary health care.

${ }^{1}$ Consultant Family physician / Quality Assurance and Academic Performance unit/ Alkindy College of Medicine / University of Baghdad. LujainAlkhazrajy@gmail.com

Received at $15 / 8 / 2017$

Accepted at 31/5/2018

\section{INTRODUCTION}

T $\mathrm{t}$ is established for the fact that most health problems of the country are primarily related to individual and group behaviors as well as life styles. Medical staffs are not in a position to address fully those health problems that mainly requires of continuous promotional health activities. In other words, maintenance of healthful life \& prevention of diseases in a society demands for professionals who can apply theories \& models of effective communication for behavior change in a desired direction ${ }^{(1)}$.

Health education is any combination of learning experiences designed to help individuals and communities improve their health, by increasing their knowledge or influencing their attitudes. ${ }^{(2)}$ It is a profession of educating people about health. Areas within this profession encompass environmental health, physical health, social health, emotional health ,intellectual health, and spiritual health. ${ }^{(3)}$ It also can be defined as the principle by which individuals and groups of people learn to behave in a manner conducive to the promotion, maintenance, or restoration of health. Health education teaches people of

all ages about how diet and exercise contribute to a healthy lifestyle. ${ }^{(4)}$
At the time of Alma-Ata declaration of Primary Health Care in 1978, health education was put as one of the components of PHC and it was recognized as a fundamental tool to the attainment of health for all. ${ }^{(5)}$

In the Eastern Mediterranean Region Several approaches have been suggested to guide health promotion efforts. These include the population health approach, the settings approach, the life course approach, and the best practices approach to health promotion. ${ }^{(6-}$

7) Rapid social changes have occurred in the Eastern Mediterranean Region in the past few decades which present a continual challenge to health in the Region. ${ }^{(8)}$

In Iraq Facilities for health education are very limited and almost a quarter of physicians and health professionals providing $\mathrm{MCH}$ services did not receive any training. The survey results also suggest that a major proportion of physicians and other health professionals lack the basic knowledge, attitudes and skills required to provide optimal $\mathrm{MCH}$ care. Since about 1990, there has been a disastrous decline in peoples' health. At a time when children's health was improving in the vast majority of countries, infant, child and maternal mortality 
rates in Iraq more than doubled. Adult mortality increased and life expectancy fell to under 60 years for men and women by 2000. Iraq is currently rated by WHO as a country with high adult and child mortality alongside much poorer countries like Afghanistan, Djibouti, Sudan and Yemen..$^{(9-10)}$

Patient participation is increasingly recognized as a key component in the redesign of health care processes and is advocated as a means to improve patient safety. The concept has been successfully applied to various areas of patient care, such as decision making and the management of chronic diseases. Among health care workers, the acceptance and promotion of patient participation are influenced by other issues, including the desire to maintain control, lack of time, personal beliefs, type of illness, and training in patientcaregiver relationships. Social status, specialty, ethnic origin, and the stakes involved also influence patient and health care worker acceptance Patient participation in hand hygiene promotion among staff to prevent health care - associated infection is discussed as an illustrative example. A conceptual model including g key factors that influence participation and invite patients to contribute to error prevention is proposed. Further research is essential to establish key determinants for the success of patient participation in reducing medical errors and in improving patient safety. ${ }^{(1-121)}$

During the past few years, patient participation has been increasingly recognized as a key component in the redesign of health care processes and successfully applied to some aspects of patient care, notably the decision-making process and the treatment of chronic illness. Recently, increasing patient participation has been recommended to improve patient safety. The World Health Organization (WHO) World Alliance for Patient Safety is actively highlighting the role that patients and their families could play in the improvement of health care. However, this field of patient participation has not been widely researched thus far. ${ }^{(13)}$

\section{METHODS}

A cross-sectional study was conducted from $1^{\text {st }}$ of January - $1^{\text {st }}$ of May 2016 in $\mathrm{Al}$ Mustansyryia and Bab-AlMuaadum PHCCs. All patients attending the Primary Health Care
Centers, who are above 18 years of age and were willing to participate, were selected in this syudy.

Permission was obtained from the Al-kindy College of Medicine,. Oral consent was obtained from each participant after brief explanation of the general purpose of the study and it is objectives.

Self-structured questionnaire, wsa used and filled, mdirect interview using Arabic language form.

Data were introduced into personal computer and SPSS (Statistical Package for the Social Sciences). V.17 for statistical analysis. Descriptive data were presented in form of number, percentages. Chi-square test was applied looking for significance of difference and level of association , $\mathrm{P}=0.05$ was considered as cut off point for level of significant education.

\section{RESULTS}

A total of 303 participants were recruited in this study. Their ages were above 18 years old, about $(65.7 \%)$ participants their age from 18-3 years old, $16.5 \%$ participants from $31-40$ years old and $10.2 \%$ participants aged from 41-50 and more older than 51 years old . Of the 303 participants, $156(51.5 \%)$ were males and $147(48.5 \%)$ were females. Their educational levels were from illiterate to the Ph.D. certification, about $0.3 \%$ of participant is illiterate, $15.2 \%$ of participants are university graduated, $28.1 \%$ of participants are having Bachelor's certification, $35.3 \%$ of participants are graduated from the high school.

There was no significant difference ( $P$ value $=0.286$ ) regarding the gender. There was significant difference $(\mathrm{P}$ value $=0.048)$ regarding the age of the participants and there was significant difference $(\mathrm{P}$ value $=0.036)$ regarding their educational level. And there was no association between health education and occupation ( $\mathrm{P}$ value=0.229). The participants occupation ranged between unemployed to employed, about $(1 \%$ of the participants are unemployed, $5.6 \%$ of participants are housewife's, $31 \%$ of the participants are employee, $53.5 \%$ of the participants are students. The association between knowledge and health education according to age, gender, educational level, occupation of participants is shown in table (1). 
The participants attitude towards health education gave a results as (negative, neutral, positive) from 303 participants the negative results were $0.7 \%$ ( 2 of 303 ), the neutral results $31.4 \%$ ( 95 of 303$)$, and the positive results were $68 \%$ ( 206 of 303).
There was no association regarding the gender, age, educational level \& occupation ( $\mathrm{P}$ value $=0.385,0.622,0.702$, and 0.831 respectively) as shown in table (2).

Table (1) : Association between knowledge \& demographic Variable

\begin{tabular}{|c|c|c|c|c|c|c|c|c|}
\hline & Varia & & & Knov & dge al & health & cation & $\mathrm{P}$ value \\
\hline \multirow{3}{*}{ Gender } & & N0. & $\%$ & Poor & Fair & Good & Total & \multirow[t]{3}{*}{0.286} \\
\hline & Male & 156 & $51.5 \%$ & 0 & 12 & 144 & 156 & \\
\hline & Female & 147 & $48.5 \%$ & 0 & 15 & 132 & 147 & \\
\hline \multirow{5}{*}{ Age } & $18-30$ & 199 & $65.7 \%$ & 0 & 21 & 178 & 199 & \multirow{5}{*}{0.048} \\
\hline & $31-40$ & 50 & $16.5 \%$ & 0 & 2 & 48 & 50 & \\
\hline & $41-50$ & 31 & $10.2 \%$ & 0 & 1 & 30 & 31 & \\
\hline & $51-60$ & 18 & $5.9 \%$ & 0 & 1 & 17 & 18 & \\
\hline & $61 \geq$ & 5 & $1.7 \%$ & 0 & 2 & 3 & 5 & \\
\hline \multirow{8}{*}{$\begin{array}{c}\text { Edu } \\
\text { level }\end{array}$} & Illiterate & 1 & $0.3 \%$ & 0 & 1 & 0 & 1 & \multirow{8}{*}{0.036} \\
\hline & Primary & 14 & $4.6 \%$ & 0 & 1 & 13 & 14 & \\
\hline & Middle sch. & 12 & $4 \%$ & 0 & 0 & 12 & 12 & \\
\hline & High sch. & 107 & $35.3 \%$ & 0 & 10 & 97 & 107 & \\
\hline & University & 46 & $15.2 \%$ & 0 & 5 & 41 & 46 & \\
\hline & Bachelor's & 85 & $28.1 \%$ & 0 & 5 & 80 & 85 & \\
\hline & Ph.D. & 6 & $2 \%$ & 0 & 0 & 6 & 6 & \\
\hline & Other Certi. & 32 & $10.6 \%$ & 0 & 5 & 27 & 32 & \\
\hline \multirow{6}{*}{ Occupation } & Employee & 94 & $31 \%$ & 0 & 5 & 89 & 94 & \multirow{6}{*}{0.229} \\
\hline & Housewife & 17 & $5.6 \%$ & 0 & 3 & 14 & 17 & \\
\hline & Retired & 8 & $2.6 \%$ & 0 & 0 & 8 & 8 & \\
\hline & Student & 162 & $53.5 \%$ & 0 & 17 & 145 & 162 & \\
\hline & Unemploye & 3 & $1 \%$ & 0 & 1 & 2 & 3 & \\
\hline & WageEarner & 19 & $6.3 \%$ & 0 & 1 & 18 & 19 & \\
\hline
\end{tabular}

Table (2): Association between attitude regarding health education \& Gender, Age, Educational level, Occupation of participants

\begin{tabular}{|c|c|c|c|c|c|c|c|c|}
\hline \multicolumn{4}{|c|}{ Variable } & \multicolumn{4}{|c|}{ Attitudes regarding health education } & P-value \\
\hline \multirow{3}{*}{ Gender } & & N0. & $\%$ & Negative & Neutral & Positive & Total & \multirow[b]{3}{*}{0.385} \\
\hline & Female & 156 & 51.5 & 0 & 46 & 101 & 147 & \\
\hline & Male & 147 & 48.5 & 2 & 49 & 105 & 156 & \\
\hline \multirow{5}{*}{ Age } & $18-30$ & 199 & 65.7 & 2 & 62 & 135 & 199 & \multirow{5}{*}{0.622} \\
\hline & $31-40$ & 50 & 16.5 & 0 & 20 & 30 & 50 & \\
\hline & $41-50$ & 31 & 10.2 & 0 & 7 & 24 & 31 & \\
\hline & $51-60$ & 18 & 5.9 & 0 & 6 & 12 & 18 & \\
\hline & $61 \geq$ & 5 & 1.7 & 0 & 0 & 5 & 5 & \\
\hline \multirow{8}{*}{$\begin{array}{l}\text { Educ. } \\
\text { level }\end{array}$} & Illiterate & 1 & 0.3 & 0 & 1 & 0 & 1 & \multirow{8}{*}{0.831} \\
\hline & Primary & 14 & 4.6 & 0 & 4 & 10 & 14 & \\
\hline & Middle & 12 & 4 & 0 & 4 & 8 & 12 & \\
\hline & High sch. & 107 & 35.3 & 1 & 32 & 74 & 107 & \\
\hline & University & 46 & 15.2 & 1 & 14 & 31 & 46 & \\
\hline & Bachelor's & 85 & 28.1 & 0 & 31 & 54 & 85 & \\
\hline & Ph.D. & 6 & 2 & 0 & 0 & 6 & 6 & \\
\hline & Other Certi. & 32 & 10.6 & 0 & 9 & 23 & 32 & \\
\hline \multirow{6}{*}{ Occupation } & Employee & 94 & 31 & 0 & 31 & 63 & 94 & \multirow{6}{*}{0.702} \\
\hline & Housewife & 17 & 5.6 & 0 & 9 & 8 & 17 & \\
\hline & Retired & 8 & 2.6 & 0 & 1 & 7 & 8 & \\
\hline & Student & 162 & 53.5 & 2 & 48 & 112 & 162 & \\
\hline & Unemployed & 3 & 1 & 0 & 1 & 2 & 3 & \\
\hline & Wage Earner & 19 & 6.3 & 0 & 5 & 14 & 19 & \\
\hline
\end{tabular}




\section{DISCUSSION}

Health education is recognized as the most effective program for improving the health status of individuals, families, communities, nations and states, reducing the costs (both financial and human) that would spend on medical treatment, so there are many studies to assess the adherence to the health education program.

The participants knowledge about health education gave a results as (good and fair) with no (poor) results the good results (276 out of $303,91.1 \%$ ) among the total study population . Fair results $8.9 \%$ of participants (27 out of 303 ) .In this study, there was no association between the knowledge and the gender of the participants ( $P$ value 2.86) because each gender had received the same level of information about health education. There was association between the knowledge and age (P value 0.048) because the higher the age of the participant the higher the information received about health education. Earlier study in Nables about Knowledge, Attitudes and Practice of Mothers regarding Antibiotic Uses for their Children in Nablus City ${ }^{(14)}$ showed that there was a significant relationship between level of knowledge and age group.

There was association between knowledge and educational level ( $\mathrm{P}$ value 0.036 ) this due to the higher the educational level received by the participants the higher the higher the information about health education given in their curriculum, in an earlier study about Dengue fever and Aedes in Malaysia ${ }^{(15)}$.

No association was seen between the level of education and the knowledge on dengue and Aedes. There was no association between knowledge and occupation of the participants ( $\mathrm{P}$ value 0.229 ) this because the health education programs and information weren't directed toward a specific occupation than the other.In an earlier study from Saudi Arabia ,the knowledge about health education regarding hand hygiene was seen to be moderate in $70 \%$ of medical students. another study had done in J.N. Medical College, Aligarh Muslim University shown that the knowledge about health education regarding hand hygiene was seen to be moderate in $75 \%$ of medical students Attitude was good among one-third of the medical students ${ }^{(16)}$.

The participants attitude towards health education gave a results as (negative, neutral, positive) from 303 participants the negative results were $0.7 \%$ ( 2 of 303), the neutral results $31.4 \%$ ( 95 of 303 ), and the positive results were $68 \%$ ( 206 of 303).

There was no association between attitude and gender ( $\mathrm{P}$ value 0.35 ) because each gender had received the same level of information regarding health education. There was no association between attitude and age $(\mathrm{P}$ value 0.622 ) this because the majority of participants in the study was between 18 to 30 (199 out of 303) There was no association between attitude and educational level ( $\mathrm{P}$ value 0.831) this because the majority of participants in the study were in high school, university and bachelor level (238 out of 303). The study mentioned in showed that there was no relationship between the level of knowledge and level of attitude ${ }^{(1)}$.

There was no association between attitude and occupation ( $\mathrm{P}$ value 0.702) this because the majority of participants in the study were students (162 out of 303).In an earlier study from Iran about Oral health knowledge, attitude, and practice in 12-year-old school children, The results of the study showed that 12-year-old schoolchildren in Iran had good knowledge and positive attitude. But oral health practice was not satisfactory ${ }^{(17)}$.

\section{CONCLUSION}

Health education is any combination of learning experiences designed to help individuals and communities improve their health increasing their knowledge or influencing their attitudes.

The research team found that there was a significant association regarding knowledge with ages and educational levels of participants ,with no association regarding the gender and occupation. There was no association regarding attitude with these variables. According to the results the knowledge of participants regarding gender, age, educational level and occupation was good and the attitudes of participants regarding these variables show positive results.

\section{REFRENCES}

1. Historical Background of Health Education and Behavioral Science https://www.ju.edu.et/cphms

2. WHO definition of health education www.who.int/topics/health_education/en/

3. e-Study Guide for Policy and Politics in Nursing and Health Care . By Reviews, Cram101 Textbook e ISBN: 9781619061002 Pages: 99 Publisher: Cram101Published Date: 01 Jan 2012 
4. R. S. Downie Collective and individual responsibilities for health $J$ Med Philos (1982) 7 (1): 43-56 DOI: $\underline{\text { https://doi.org/10.1093/jmp/7.1.43 }}$

5. Declaration of Alma-Ata $\{\mathrm{WHO}\}$ : www. who.int/publications/almaata_declaration_en.pdf

6. The historical development of public health Am J Public Health (N Y). Dec; 9(12): 907-918. PMCID: PMC1362651.

7. A strategy for health promotion in the Eastern Mediterranean Region 2006-2013 \{WHO $\}$ www.emro.who.int/dsaf/dsa794.pdf

8. Health topics. https://medlineplus.gov/ healthtopics.html

9. Health In Iraq second edition $\{\mathrm{WHO}\}$

www.who.int/hac/crises/irq/background/Iraq_Healt $\mathrm{h}$ _in_Iraq_second_edition.pdf

10- public health directorate. Ministry of health .Iraq http://www.phd.iq/index.php

11- Infection Control Program, University of Geneva Hospitals and Faculty of Medicine, 4 Rue Gabrielle-Perret Gentil, 1211 Geneva 14, Switzerland.

12- Kennedy JF. Special message to the Congress on protecting the consumer interest. In: Public Papers of the Presidents of the United States March15, 1962 Washington, DC: US Government Printing Office; 1962:93:236

13. World Health Organization. World Alliance for Patient Safety. Global Patient Safety Challenge 2005-2006: Clean Care is Safer Care Geneva, Switzerland: World Health Organization; 2005:125

14 - Knowledge, Attitudes and Practice of Mothers regarding Antibiotic Uses for their Children in Nablus City 2016. https://fmhs.najah.edu/node/2842
15. Azzam al Kadi, Sajad Ahmad Salati: Hand Hygiene Practices among Medical Students, Interdisciplinary Perspectives on Infectious Diseases, Volume 2012 (2012), Article ID 679129, 6 pages

16. Saira Mehnaz, Ali Jafar Abedi, Sadia Rehman Safwi, Najam Khalique M.Athar Ansari, Zulfia Khan: KAP study of hand hygiene among medical and nursing students in a tertiary teaching hospital International Journal of Sciences \& Applied Research, 2(6), 2015; 29-39

17. Maryam Rad1, Arash Shahravan1, Ali Akbar Haghdoost2Oral health knowledge, attitude, and practice in 12-year-old schoolchild ren in Iran: .journal of international of society of preventive \& community dentesry Volume: 5| Issue : 5 | Page : 419-424 